\title{
Nodule formation in soybeans by exopolysaccharide mutants of Rhizobium fredii USDA 191
}

\author{
Young H. Ko† and Randall GaYdA* \\ Department of Microbiology, Louisiana State University and Agricultural \& Mechanical College, Baton Rouge, \\ LA 70803, USA
}

(Received 10 July 1989; revised 1 September 1989; accepted 18 September 1989)

\begin{abstract}
Production of exopolysaccharides by Rhizobium has been linked with efficient invasion and nodulation of leguminous plant roots by the bacteria. Exopolysaccharide-deficient (exo) mutants of Rhizobium fredii USDA 191 were isolated following Tn5-insertion mutagenesis. Five phenotypically unique exo mutants were investigated for exopolysaccharide synthesis and their ability to nodulate soybeans. The exopolysaccharides produced by these mutants were analysed for polysaccharide composition by column chromatography and thin-layer chromatography. Two mutants designated exo-3 and exo-5 were deficient in both neutral glucan and exopolysaccharide synthesis, but each induced some functional nodules on Glycine max (Peking). The remaining three mutants (exo1, exo-2 and exo-4) synthesized neutral glucans at levels higher or lower than those in the wild-type and exhibited partial exopolysaccharide deficiencies. The data imply that neither exopolysaccharides nor neutral glucans are essential for the induction of determinate nodules by $R$. fredii.
\end{abstract}

\section{Introduction}

The induction of nitrogen-fixing nodules on the roots of host legumes by Rhizobium and Bradyrhizobium bacteria is a multistep process involving interactions between the plant and its symbiont (see reviews by Halverson \& Stacey, 1986; Keen \& Staskawicz, 1988). Bacterial lipopolysaccharides and exopolysaccharides have been implicated as early bacterial signals in nodule development (Djordjevic et al., 1987; Finan et al., 1985; Gardiol et al., 1987; Leigh et al., 1985). Exopolysaccharides are composed of capsular polysaccharides (CPS) and extracellular polysaccharides (EPS) that differ chiefly in their degrees of polymerization (Tsien \& Schmidt, 1981). Exopolysaccharide-deficient (exo) mutants of several Rhizobium species do not form normal nitrogen-fixing nodules; instead, they induce abnormal pseudonodules in legume roots which are devoid of bacteroids (Djordjevic et al., 1987; Finan et al., 1985; Noel et al., 1986; Vandenbosch et al., 1985). Several hypotheses for the functional role(s) of exopolysaccharides in the bacterial invasion process have been proposed. Exopolysacchar-

† Present address: Department of Food Technology, Cheju National University, Cheju, Chejudo 690-121, Korea.

\footnotetext{
Abbreviations: CPS, capsular polysaccharides; EPS, extracellular polysaccharides.
}

ides may function as signal molecules that induce host initiation of infection thread formation and allow the rhizobia to enter the plant (Downie \& Johnston, 1986; Halverson \& Stacey, 1986). They may function to allow the growth of the bacteria within the infection thread without evoking the plant defence mechanisms (Downie \& Johnston, 1986; Verma \& Nadler, 1984). They may act as host specificity factors which enable the bacteria to bind to specific plant lectins (Halverson \& Stacey, 1986; Keen \& Staskawicz, 1988). In short, exopolysaccharides may be functioning as direct inducers, indirect protectors, or both, in the bacterial penetration process.

The exopolysaccharides synthesized by various Rhizobium species can be divided into acidic polysaccharide and neutral polysaccharide components. Acidic exopolysaccharides are composed of hexoses and uronic acids (Huber et al., 1984; Mort \& Bauer, 1980, 1982; Robertsen et al., 1981). The acidic exopolysaccharides of $R$. fredii USDA 191 contain uronic acid, mannose, galactose and glucose in an approximately $1: 1: 1: 1$ ratio and are also pyruvated ( $\operatorname{Lim} \&$ Tan, 1983). This is quite different from the reported composition of the exopolysaccharide from the more extensively studied species, $R$. meliloti 1021, which contains seven $\beta$-linked glucoses and one $\beta$-linked galactose and is modified by pyruvylation, acetylation and succinylation (Aman et al., 1981). The neutral polysaccharide components contain primarily $\beta$ - 
glucans (York et al., 1980). Approximately 5 to $10 \%$ of the total polysaccharides secreted by fast-growing Rhizobium species are composed of $\beta$-2-linked glucans (York et al., 1980). The $\beta$-glucans are cyclic compounds with about 20 glucose residues. There is a strong correlation between $\beta$-1,2-glucan synthesis and plant attachment in both Rhizobium infection and Agrobacterium virulence (Cangelosi et al., 1987).

The present work was performed to determine if exopolysaccharide synthesis is a strict requirement for the induction of soybean nodulation by $R$. fredii USDA 191. Exopolysaccharide-deficient mutants of $R$. fredii USDA 191 were created by transposon $\operatorname{Tn} 5$ insertion mutagenesis, and their ability to induce nodulation in soybean roots was examined.

\section{Methods}

Biological materials. Bacterial strains and plasmids are listed in Table 1. Escherichia coli strains were maintained on Luria-Bertani (LB) medium (Maniatis et al., 1982) and $R$. fredii on mannitol/salt/yeast extract (MSY) medium (Lim \& Shanmugam, 1979). Antibiotics were added to the media at the following concentrations: $25 \mu \mathrm{g} \mathrm{ml}^{-1}$ for kanamycin sulphate and chloramphenicol for $E$. coli; and $40 \mu \mathrm{g} \mathrm{ml}^{-1}$ for nalidixic acid, $50 \mu \mathrm{g} \mathrm{ml}^{-1}$ for kanamycin sulphate, $25 \mu \mathrm{g} \mathrm{ml}^{-1}$ for streptomycin sulphate and $10 \mu \mathrm{g} \mathrm{ml}^{-1}$ for tetracycline hydrochloride for $R$. fredii. Seeds of wild-type soybean, Glycine soja and Glycine max (Peking), obtained from R. Tully (USDA-ARS, Beltsville, Maryland, USA), were used for nodulation tests.

Mutagenesis and screening for exo mutants. Filter mating was done with a slight modification of the procedure of Hom et al. (1984). Cells from exponential-phase cultures of $E$. coli MM294A(pRK602) were mixed with cells of $R$. fredii YKL999, collected on a nitrocellulose membrane filter, washed three times with $0.9 \% \mathrm{NaCl}$, and incubated overnight on yeast extract/salt (YS) agar plates (Lim \& Shanmugam, 1979) at $28^{\circ} \mathrm{C}$. Cells were washed off the filter with YS broth and dilutions were spread on MSY agar plates containing nalidixic acid, kanamycin sulphate and streptomycin sulphate (Selvaraj \& Iyer, 1984). Small non-mucoid transconjugants were selected and purified by restreaking on the same selection medium.

EPS production was quantified from $7 \mathrm{ml}$ of late-exponential-phase cultures grown in mannitol/glutamate (MG) medium (Sherwood, 1970) at $28^{\circ} \mathrm{C}$. The culture samples were centrifuged at $12000 \mathrm{~g}$ for $20 \mathrm{~min}$ to pellet the cells and EPS was precipitated from $5 \mathrm{ml}$ of supernatant culture fluid by the addition of 2 vols acetone (Tully, 1985). This precipitate was washed three times with acetone/water $(2: 1, \mathrm{v} / \mathrm{v})$, dried, and dissolved in $1 \%(\mathrm{v} / \mathrm{v}) \mathrm{H}_{2} \mathrm{SO}_{4}$. Hexose content was determined by the anthrone method (Morris, 1948). The addition of acetone to the medium does not precipitate neutral glucans (Dudman \& Jones, 1980).

Plant nodulation test. Method I. Seeds of $G$. soja were surface sterilized by soaking in concentrated $\mathrm{H}_{2} \mathrm{SO}_{4}$ for $15 \mathrm{~min}$, rinsing five times with sterile water for $5 \mathrm{~min}$, washing with $50 \%(\mathrm{v} / \mathrm{v})$ ethanol for $5 \mathrm{~min}$, and rinsing again three times with sterile water for $2 \mathrm{~min}$. Sterile seeds were germinated on $0.5 \%(\mathrm{w} / \mathrm{v})$ water agar at room temperature in darkness for 3-4 d. Seedlings were inoculated by dipping the roots in a late-exponential-phase culture of bacteria for $30-60 \mathrm{~s}$, and then transplanted to vermiculite containing nitrogen-free salt medium (Schwinghamer, 1960). Plants were harvested after 4 weeks of incubation in a growth chamber under fluorescent light with a $14 \mathrm{~h}$ photoperiod at $22^{\circ} \mathrm{C}$ (night) and $30^{\circ} \mathrm{C}$ (day). Every observable change in plant root tissue was noted. Four to five seedlings were inoculated with each bacterial strain and each experiment was performed twice.

Method II. Seeds of G. max (Peking) were surface-sterilized by successive soaking in $50 \%(\mathrm{v} / \mathrm{v})$ ethanol $(5 \mathrm{~min})$ and $50 \%(\mathrm{w} / \mathrm{v})$ sodium hypochlorite $(5 \mathrm{~min})$ and rinsing with copious amounts of sterile deionized water (Pueppke, 1983). Bacteria from late-exponential-phase cultures were collected by centrifugation, washed, and resuspended in water at a final concentration of $10^{8}$ cells $\mathrm{ml}^{-1}$. Surface-sterilized seeds were soaked in this inoculum for $1 \mathrm{~h}$ and planted in vermiculite containing nitrogen-free salt medium (Schwinghamer, 1960) with $0.5 \mathrm{ml}$ of the inoculum. The seeds were initially incubated in darkness for 4-5 $\mathrm{d}$ followed by the same regimen of temperature and light as above. Subsequent harvest and examination procedures were as described above.

Recovery of bacteroids from nodules. Nodules were excised from the roots and surface-sterilized in $50 \%(\mathrm{w} / \mathrm{v})$ sodium hypochlorite for $2 \mathrm{~min}$ followed by five rinses with sterile water for $5 \mathrm{~min}$. The nodules were then crushed in MSY medium and plated on selective tryptone/yeast extract (TY) agar plates (Jagadish \& Szalay, 1984) to verify that the bacteroids which were recovered exhibited the same exo phenotype and antibiotic resistance as the original inoculum.

Scanning electron microscopy. Nodules were fixed with glutaraldehyde, dehydrated with ethanol, critical-point dried, sputter-coated (Postek et al., 1980), and examined with an Hitachi S-500 scanning electron microscope.

Fractionation and analysis of exopolysaccharide. For size fractionation of EPS, $R$. fredii strains were grown in MG broth at $30^{\circ} \mathrm{C}$ to an optical density at $600 \mathrm{~nm}$ of $0 \cdot 6-0 \cdot 8$. Supernatant culture fluid was obtained after centrifugation at $6000 \mathrm{~g}$ for $30 \mathrm{~min}$ at $4{ }^{\circ} \mathrm{C}$. The culture fluid was freeze-dried, dissolved in a minimal volume of water, and dialysed in $10 \mathrm{~mm}$-phosphate buffer ( $\mathrm{pH} 7.0$ ) containing $0.02 \%$ sodium azide (elution buffer) at $4{ }^{\circ} \mathrm{C}$ in dialysis tubing with a molecular mass cut-off of $1000 \mathrm{Da}$.

For CPS isolation, bacteria were grown under the same conditions as above, bacterial cells were pelleted by centrifugation at $6000 \mathrm{~g}$ for $30 \mathrm{~min}$, washed with phosphate-buffered saline (pH 7.2) (Mort \& Bauer, 1980), and then resuspended in the same buffer for $6 \mathrm{~d}$ at $4{ }^{\circ} \mathrm{C}$. The supernatant culture fluid containing the CPS was collected by centrifugation at $6000 \mathrm{~g}$ for $30 \mathrm{~min}$ at $4{ }^{\circ} \mathrm{C}$, concentrated by freezedrying and dialysed against deionized water.

EPS or CPS samples were size-fractionated by column chromatography. Bio-Gel A-5m (BioRad) columns $(1.6 \times 40 \mathrm{~cm})$ were loaded with polysaccharide samples normalized for culture optical density and percentage of total crude supernatant culture fluid. The elution rate was approximately $0.07 \mathrm{ml} \mathrm{min}^{-1}$ with elution buffer at $4{ }^{\circ} \mathrm{C}$. Fractions of $1 \mathrm{ml}$ were collected, and their hexose contents were determined by anthrone analysis.

EPS samples were further fractionated into acidic and neutral EPS by anion-exchange column chromatography. EPS samples were loaded on a DEAE-Sephadex A-50 (Pharmacia) column $(6.5 \mathrm{ml})$ at $25^{\circ} \mathrm{C}$ which was subsequently washed with deionized water until no hexose was detected in the effluent by the phenol/sulphuric acid method (Ashwell, 1966). Bound EPS was eluted from the column with $1 \mathrm{M}$ sodium acetate. For the identification of neutral glucans, those fractions not binding to the anion exchanger were hydrolysed with $0.5 \mathrm{M}-\mathrm{HCl}$ at $100^{\circ} \mathrm{C}$ for $5-20 \mathrm{~min}$ (Gardiol et al., 1987). The products of acid hydrolysis were separated on silica gel thin-layer plates (Analtech), using a solvent mixture of 2-propanol/acetic acid/water $(27: 4: 9$, by vol.), and were visualized with orcinol ferric chloride reagent (Sigma) (Bonn et al., 1986). 
Plasmid separation and DNA hybridization. Plasmids were separated by agarose gel electrophoresis. Lysis of bacteria within the well (Hynes et al., 1986) was used to separate the large plasmids of $R$. fredii by agarose gel electrophoresis. DNA was transferred to nitrocellulose filters by the method of Southern (Maniatis et al., 1982) after partial depurination cleavage (Wahl et al., 1979). A biotin-labelled Tn5 probe (Leary et al., 1983) was prepared by nick-translating pSUP2021 DNA using a biotin-11-dUTP nucleotide (Bethesda Research Laboratories). DNA-DNA hybridization and detection of hybrids were done according to the manufacturer's procedure.

Introduction of plasmids containing $R$. meliloti exo genes into $R$. fredii exo mutants. Plasmids carrying functional exo genes from $R$. meliloti were obtained from G. Walker: pD56 $($ exo $F / B)$, pD2 (exoB), pD5 (exoD), pD34 (exoA), pD15 (exoC) (Finan et al., 1985). These plasmids, which are derivatives of the broad host-range plasmid pLAFR 1 , were transferred individually into the $R$. fredii exo mutants by triparental mating. The triparental matings were done using the helper plasmid pRK2013 by the filter mating procedure of Hom et al. (1984). Transconjugants were screened on MSY agar containing nalidixic acid, kanamycin sulphate and tetracycline hydrochloride.

\section{Results}

\section{Isolation of exo mutants}

Suicide plasmid pRK602 containing transposon $\operatorname{Tn} 5$ was mobilized from $E$. coli MM294A(pRK602) to $R$. fredii YKL999 by filter mating. From this mating, kanamycinresistant transconjugants ( $\operatorname{Tn} 5$ insertion mutants) of $R$. fredii were obtained at a frequency of $1 \times 10^{-5}$ per recipient. exo mutants with a nonmucoid appearance on the selective medium were isolated at a frequency of about $1 \times 10^{-3}$. Eighty-five exo mutants were isolated and, of these, five phenotypically unique, nonmucoid colonies were chosen for further study (Table 1). Wildtype $R$. fredii colonies were highly mucoid in appearance and produced large, watery and opaque colonies. $R$. fredii YKL224 (exo-1) produced colonies that were nonmucoid and whiter in colour than the wild-type strain. YKL224 produced only $4 \%$ of the acetone-precipitable EPS of wild-type. YKL257 (exo-2) was slightly mucoid and produced $43 \%$ of the acetone-precipitable EPS of wild-type. YKL285 (exo-3) was translucent and produced $12 \%$ of the amount of EPS compared to the wildtype strain. R. fredii YKL288 (exo-4) and YKL293 (exo5 ) were nonmucoid and produced only $2 \%$ and $4 \%$, respectively, of acetone-precipitable EPS compared to the wild-type. In addition, YKL293 (exo-5) grew slowly and formed smaller colonies than the other exo mutants.

$R$. fredii USDA 191 contains at least three large plasmids of $65 \mathrm{~kb}, 229 \mathrm{~kb}$, and $>300 \mathrm{~kb}$ in size (Appelbaum et al., 1985; Heron \& Pueppke, 1984). DNA hybridizations probing for $\mathrm{Tn} 5$ insertions within these plasmids were performed on the five exo mutants. Bacteria were lysed within an agarose gel well, the three large plasmids were separated by agarose gel electro-
Table 1. Bacterial strains and plasmids

\begin{tabular}{|c|c|c|}
\hline $\begin{array}{l}\text { Strains and } \\
\text { plasmids }\end{array}$ & Characteristics & References \\
\hline \multicolumn{3}{|l|}{ Strains } \\
\hline $\begin{array}{l}\text { Escherichia coli } \\
\text { SM10 }\end{array}$ & $\begin{array}{l}\mathrm{C} 600, \operatorname{rec} A, \mathrm{Mu}_{\mathrm{c}}^{+} \text {with } \\
\text { integrated plasmid } \\
\mathrm{RP} 4-2-\mathrm{Tc}:: \mathrm{Mu}, \mathrm{Km}^{r} ; \text { host } \\
\text { of pSUP2021 and } \\
\text { pSUP202 }\end{array}$ & Simon et al. (1983) \\
\hline MM294A & $\begin{array}{l}\text { pro- } 82 \text { thi-l endoAl hsdR17 } \\
\text { supE } 44, \text { host of pRK } 602\end{array}$ & Leigh et al. (1987) \\
\hline \multicolumn{3}{|l|}{ Rhizobium fredii } \\
\hline USDA 191 & Wild-type & Barbour et al. (1985) \\
\hline YKL224 & $\begin{array}{l}\text { Tn5-induced exo-1 mutant } \\
\text { of YKL999, } \mathrm{Km}^{\mathrm{r}} \mathrm{Sm}^{\mathrm{r}}\end{array}$ & \\
\hline YKL257 & As YKL224, but exo-2 & \\
\hline YKL285 & As YKL224, but exo-3 & This study \\
\hline YKL288 & As YKL224, but exo-4 & This study \\
\hline YKL293 & As YKL224, but exo-5 & \\
\hline YKL999 & $\begin{array}{l}\mathrm{Na}^{\mathrm{r}} \text { derivative of } \\
\text { USDA } 191\end{array}$ & \\
\hline \multicolumn{3}{|l|}{ Plasmids } \\
\hline pRK602 & $\begin{array}{l}\text { pRK2013 } \mathrm{Nm}:: \operatorname{Tn} 9 \\
\text { containing Tn } 5, \mathrm{Km}^{\mathrm{r}} \mathrm{Cm}^{\mathrm{r}}\end{array}$ & Leigh et al. (1987) \\
\hline pSUP202 & $\mathrm{Ap}^{r} \mathrm{Cm}^{\mathrm{r}} \mathrm{Tc}^{\mathrm{r}}$ & Simon et al. (1983) \\
\hline pSUP2021 & $\begin{array}{l}\text { pSUP202 Tc::Tn5, } \\
\text { Ap }^{r} \mathrm{Cm}^{r} \mathrm{Km}^{\mathrm{r}}\end{array}$ & Simon et al. (1983) \\
\hline pRK2013 & Helper, $\mathrm{Km}^{\mathrm{r}}$ & Ditta et al. (1980) \\
\hline
\end{tabular}

$\mathrm{Km}$, kanamycin; $\mathrm{Sm}$, streptomycin; $\mathrm{Na}$, nalidixic acid; $\mathrm{Nm}$, neomycin; $\mathrm{Cm}$, chloramphenicol; Ap, ampicillin; $\mathrm{Tc}$, tetracycline.

phoresis and DNA was transferred to nitrocellulose filters. A biotin-labelled probe of pSUP2021 containing Tn5 was hybridized to the DNA on the nitrocellulose filters. A positive hybridization signal was detected from E. coli MM294A(pRK602) plasmid DNA as well as pSUP2021 unlabelled DNA, but was not detected from plasmid DNAs from any of the $R$. fredii exo mutants or $R$. fredii YKL999. Positive hybridization signals were detected around the agarose gel well on the top of the agarose gel where large chromosomal DNA fragments migrate (data not shown) suggesting that the Tn5 insertions may be located in the chromosome.

\section{Analysis of the exopolysaccharides produced by the exo mutants}

Acetone-precipitable EPS is a measure of bulk EPS. In order to determine whether the variant levels observed were due to changes in specific polysaccharide fractions, EPS samples from the culture fluid were separated by size on a Bio-Gel A-5m column (Fig. 1). Culture fluid from wild-type $R$. fredii, YKL999, contained a set of heterogeneous polysaccharides. High-molecular-mass material eluted in fractions just after the void volume. 

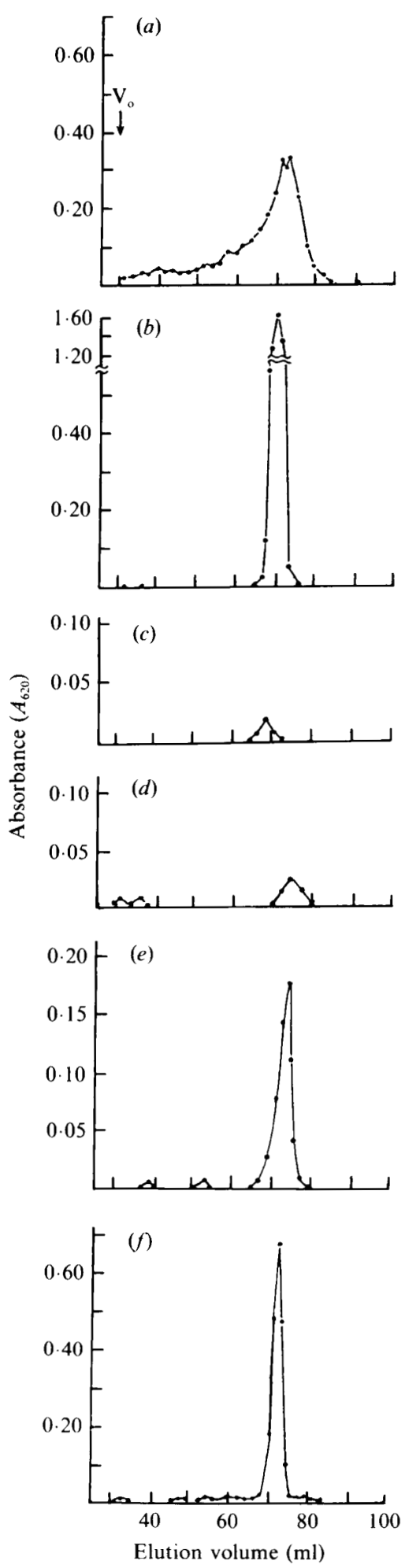

Fig. 1. Size-fractionation of EPS from supernatant culture fluid of wild-type and exo mutants. Culture samples were separated on Bio-Gel A $-5 \mathrm{~m}$ column, and the hexose content of the fractions was determined as described in Methods. The curves were normalized with respect to culture density and volume of culture fluid loaded. $\mathrm{V}_{0}$ void volume of the column. (a) YKL999 wild-type, (b) YKL224 (exo-1), (c) YKL293 (exo-5), (d) YKL285 (exo-3), (e) YKL288 (exo-4), (f) YKL257 (exo-2).
Low-molecular-mass material continued to be eluted up to an elution volume of $85 \mathrm{ml}$, with a major peak between 65 and $75 \mathrm{ml}$ (Fig. 1 a). In contrast, all the exo mutants possessed polysaccharide that was much less heterogeneous. EPS extracted from strain YKL224 (exo-I) (Fig. $1 b$ ) eluted as one sharp peak between volumes 65 and $75 \mathrm{ml}$. YKL257 (exo-2) (Fig. 1f) and YKL288 (exo-4) (Fig. $1 e$ ) synthesized polysaccharides that were similar to YKL224 polysaccharide but with the addition of two minor peaks of high-molecular-mass polysaccharide fractions. exo mutants YKL285 (exo-3) (Fig. 1d) and YKL293 (exo-5) (Fig. 1c), displayed little polysaccharide even within the major peak. This residual peak had a brownish colour instead of the normal greenish-blue colour observed in YKL999, YKL224, YKL257 and YKL288, which suggests that it is not likely to be a hexose fraction. YKL285 had a trace amount of highmolecular-mass polysaccharide eluting after the void volume.

Since EPS consists of both acidic and neutral components, the polysaccharides were further fractionated on DEAE-Sephadex columns to examine the relative contributions of both types. Less than $5 \%$ of the total EPS of the wild-type was neutral polysaccharide. In contrast, EPS of strain YKL224 consisted of $55 \%$ neutral and $45 \%$ acidic polysaccharide (Fig. 2a). EPS of YKL288 was primarily of neutral polysaccharide, which in turn constituted $70 \%$ of the total EPS (Fig. $2 b$ ).

Complete acid hydrolysis of neutral EPS yielded only a single component, corresponding to glucose on silica gel thin-layer plates. Partial hydrolysis, on the other hand, produced glucose polymers of varying length. Thus, the neutral EPS fraction is probably a glucan. In Table 2, the amount of neutral glucan produced by the exo mutants is presented for comparison with the wild-type.

Since no notable differences were discernible between YKL285 (exo-3) and YKL293 (exo-5) based on EPS analysis, the production of CPS was examined in these strains. CPS from the wild-type strain, when analysed on a Bio-Gel A-5m column, migrated as a single peak of low-molecular-mass polysaccharide (Fig. 3a). Both YKL285 (Fig. 3b) and YKL293 (Fig. 3c) mutants exhibited very little if any CPS.

Complementation of $R$. fredii exo mutants EPS with plasmids containing $R$. meliloti exo genes

In $R$. meliloti 1021, six genetic loci involved in exopolysaccharide synthesis have been identified by gene cloning and complementation assays (Finan et al., 1985; Leigh et al., 1985). Four of the exo mutations were mapped to megaplasmids within $R$. meliloti, and two mutations were located on the chromosome (Finan et al., 


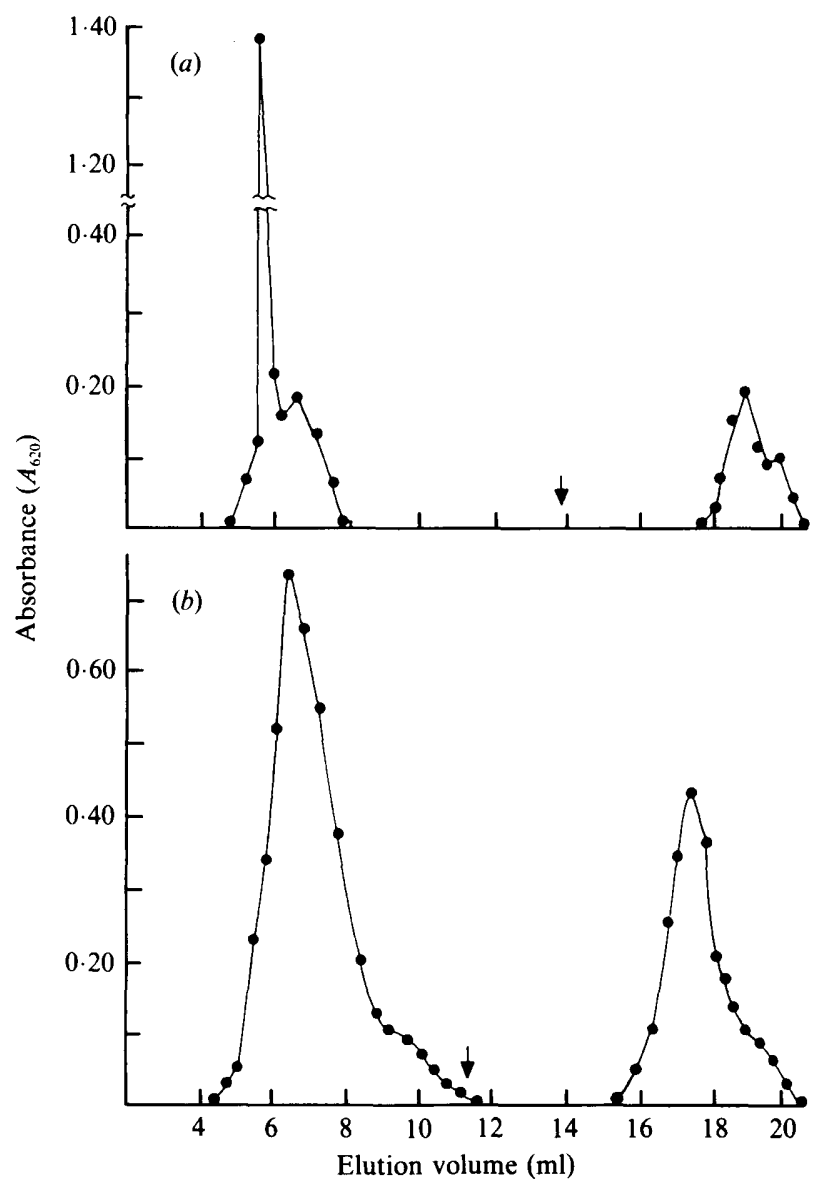

Fig. 2. Charge separation of neutral and acidic EPS. Equal volume of concentrated supernatant culture fluid from two exo mutants with similar optical density were separated on DEAE-Sephadex A-50 column. The column was eluted first with water, until no carbohydrate was detected in the effluent, and then with aqueous $1 \mathrm{M}$-sodium acetate. The arrow indicates the point of addition of $1 \mathrm{M}$-sodium acetate. (a) YKL224 (exo-I), (b) YKL288 (exo-4).
1985; Leigh \& Lee, 1988). Plasmids carrying functional exo genes from $R$. meliloti were obtained: pD56 (exoF/B), pD2 (exoB), pD5 (exoD), pD34 (exoA), pD15 (exoC) (Finan et al., 1985). They were introduced individually into the exo mutants of $R$. fredii using triparental matings. The restoration of exopolysaccharide production was assayed. Transconjugants of YKL288 by pD56 (exoF/B), but not by pD2 (exoB), produced only $66 \%$ as much EPS as the wild-type, YKL999. Transconjugants of YKL293 by pD15 (exoC) produced $86 \%$ as much EPS as the wild-type. YKL285, YKL257 and YKL224 were not affected in EPS synthesis by the introduction of any plasmid encoding an exo gene from R. meliloti.

\section{Nodulation ability of the exo mutants}

The five $R$. fredii exo mutants were examined for ability to induce nodulation of soybean plants. The nodules that formed on the plant roots consisted of two types. The first class were typical spherical nodules that were large, determinate, and pink-pigmented. Bacteroids were recovered from these nodules after surface sterilization of the nodule. The second class of nodules were small, irregular in shape, and white, with a vascular bundle in the centre. No bacteroids could be recovered from these atypical nodules. Scanning electron micrographs of both nodule types are shown in Fig. 4 . No bacteroids could be seen in cross-sections of the atypical 'pseudonodules' (Fig. $4 e, f$ ), whereas clusters of bacteroids were found inside the cortical layer of typical nodules (Fig. $4 c, d$ ).

The average numbers of nodules induced per plant by the wild-type and exo mutants of $R$. fredii USDA 191 on $G$. soja and on $G$. max are presented in Table 2.

Table 2. Comparison of the nodulation ability and exopolysaccharide production of $R$. fredii USDA 191 wild-type and exo mutants

\begin{tabular}{|c|c|c|c|c|c|}
\hline \multirow[b]{2}{*}{ Strains } & \multicolumn{2}{|c|}{$\begin{array}{l}\text { Number of nodules } \\
\text { per plant }(T / A)^{*}\end{array}$} & \multirow{2}{*}{$\begin{array}{l}\text { Neutral glucan } \\
\text { fraction } \dagger \\
(\% \text { of wild-type })\end{array}$} & \multirow{2}{*}{$\begin{array}{c}\text { CPS } \ddagger \\
\text { (\% of wild-type) }\end{array}$} & \multirow{2}{*}{$\begin{array}{c}\text { EPS } \S \\
(\% \text { of wild-type) }\end{array}$} \\
\hline & G. soja & G. $\max$ & & & \\
\hline YKL999 (wild-type) & $1 \cdot 0^{a} / 10$ & $3 \cdot 4^{c} / 0 \cdot 0$ & $100 \cdot 0$ & $100 \cdot 0$ & 100 \\
\hline YKL224 (exo-I) & $1 \cdot 2^{a} / 20$ & $0 \cdot 1^{f} / 2 \cdot 1$ & $235 \cdot 0$ & ND & 4 \\
\hline YKL257 (exo-2) & $1 \cdot 0^{a} / 32$ & $0 \cdot 1 f / 4 \cdot 7$ & $100 \cdot 0$ & ND & 43 \\
\hline YKL285 (exo-3) & $1 \cdot 3^{a} / 26$ & $1 \cdot 3^{\text {dee }} / 15 \cdot 2$ & $2 \cdot 5$ & $4 \cdot 0$ & 12 \\
\hline YKL288 (exo-4) & $0 \cdot 4^{a, b} / 15$ & $2 \cdot 0^{d / 3} \cdot 4$ & $25 \cdot 0$ & ND & 2 \\
\hline YKL293 (exo-5) & $0.0^{b} / 16$ & $0.5^{e f} / 9.4$ & 1.0 & $4 \cdot 2$ & 4 \\
\hline Control & $0 \cdot 0^{b} / 0 \cdot 0$ & $0.0 / 0.0$ & NA & NA & NA \\
\hline
\end{tabular}

ND, not determined. NA, not applicable.

* Four to five seedlings of soybean were inoculated with each strain for two separate experiments and repeated once. The numbers are LS (least squares) means of typical (T) nodules and average numbers of atypical (A) nodules per plant. LS means superscripted by the same letter are not significantly different $(P=0.05)$ according to least significant difference tests performed on individual LS means.

+ Neutral EPS fraction was determined from the elution profile on a DEAE-Sephadex A-50 column.

$\ddagger$ CPS was estimated from the elution profiles on a Bio-gel A-5m column (Fig. 3 ).

$\S$ EPS was determined by addition of 2 vols acetone to culture supernatant. 

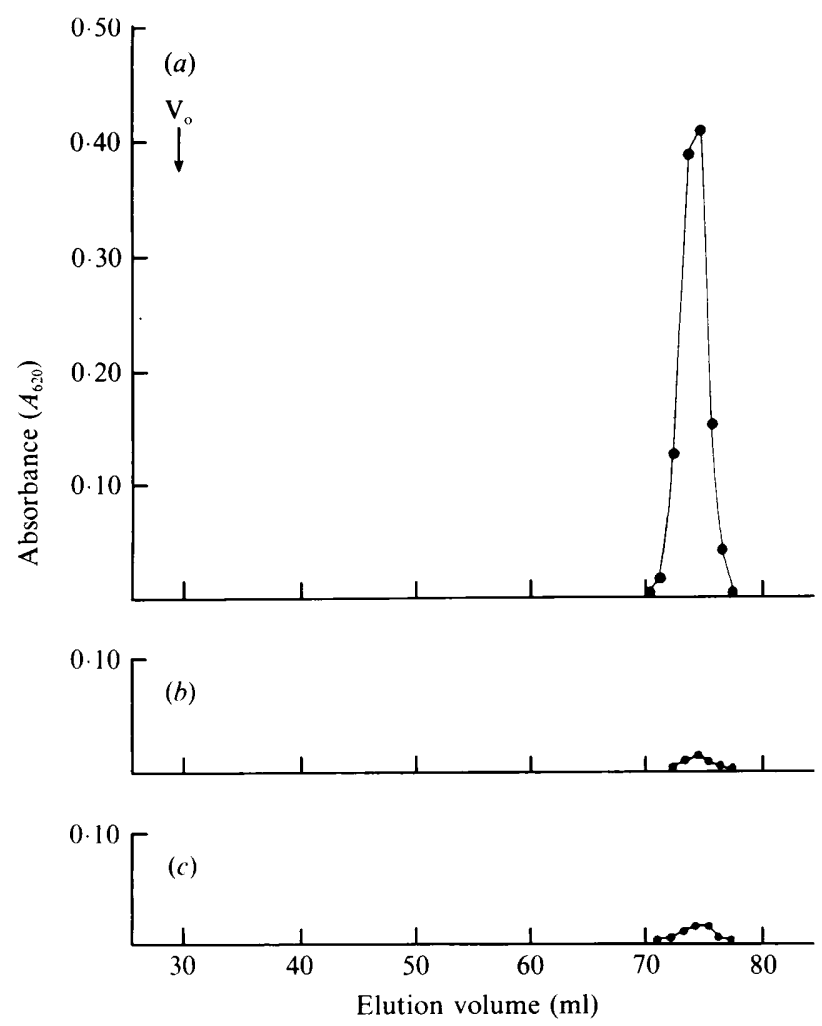

Fig. 3. Size fractionation of CPS from wild-type and two exo mutants of $R$. fredii USDA 191. CPS isolated as described in Methods were separated on a Bio-Gel A- $5 \mathrm{~m}$ column. The curves were normalized with respect to culture density and volume of culture fluid loaded. $\mathrm{V}_{0}$, void volume of the column. (a) YKL999 (wild-type), (b) YKL285 (exo-3), (c) YKL293 (exo-5).

YKL293 (exo-5) was the only mutant strain that did not induce any typical spherical nodules on $G$. soja. The other four mutant strains induced typical nodules comparable in number to those induced by the wild-type strain YKL999. Bacteria recovered from the typical nodules induced by the exo mutants were phenotypically the same with regard to EPS production and antibiotic resistance as the inoculating bacteria. The low number of spherical nodules observed per plant (approximately one per root) was typical for wild-type $R$. fredii infection of this soybean (Heron \& Pueppke, 1984). Interestingly, exo-5 mutant YKL293, as well as other exo strains and the wild-type, induced the formation of many small atypical 'pseudonodules' on the infected roots of G. soja.

$R$. fredii was originally isolated from G. max (Peking) and this plant appears to be a preferred host (Keyser et al., 1982). When these same exo mutants were tested for nodulation on $G$. max, the nodulation efficiencies of mutants were different from those obtained on $G$. soja. Soybeans inoculated with YKL224 (exo-l) and YKL257 (exo-2) developed spherical nodules in only one plant in ten, though all plants produced two or more atypical pseudonodules. In contrast to G. soja, G. max inoculated with YKL293 (exo-5) developed typical nodules $50 \%$ of the time, and when inoculated with YKL288 (exo-4) it nodulated only slightly less than when inoculated with wild-type. A comparison of the nodule induction by $R$. fredii exo mutants and EPS production (last column of Table 2) indicated no strong correlation between EPS levels and ability to induce nodulation.

\section{Discussion}

The major question addressed in this paper is whether exo mutants of $R$. fredii USDA 191 are adversely affected in the induction of soybean nodulation. In $R$. melilotialfalfa symbiosis, bacterial exopolysaccharide synthesis was found to be essential in the induction of nodule formation: all the exo mutants of R. meliloti 1021 except exo $D$ showed lack of nodule invasion and induced only pseudonodules in alfalfa roots (Leigh et al., 1985, 1987; Leigh \& Lee, 1988). Similarly, exo mutants of $R$. leguminosarum were found not to induce effective nodule formation on peas (Borthakur et al., 1986). Both $R$. meliloti and $R$. leguminosarum form cylindrical indeterminate nodules on the roots of their respective hosts. In fact, the requirement for sufficient EPS appears to be stringent only for indeterminate nodule formation.

When Chen et al. (1985) tested Tn5-induced mutants of Rhizobium NGR234 (a strain with a broad host range) for nodulation on determinate and indeterminate nodule-forming hosts, these exo mutants induced normal-tosmall nodules on the determinate host's roots, but induced only small callus-like structures on the indeterminate host's roots. Similarly, Borthakur et al. (1986), working with the same gene found that a single exo mutation in $R$. leguminosarum made the bacterium ineffective in the nodulation of peas, but in $R$. phaseoli had no effect on nodulation in beans. Thus, the dependence on exopolysaccharide synthesis for nodulation of plants appears to be stronger for the indeterminate nodule structure.

Our data (Table 2) with exo mutants of $R$. fredii USDA 191 are consistent with the above correlation. $R$. fredii USDA 191 induces determinate nodules on soybeans. There was no apparent absolute requirement of exopolysaccharides for nodulation of G. $\max$ or G. soja. Four exo mutants of $R$. fredii, YKL224 (exo-1), YKL257 (exo-2), YKL285 (exo-3) and YKL288 (exo-4) induced typical spherical nodules on $G$. soja. Only one mutant, YKL293 (exo-5), was found unable to induce nodulation in this plant species. However, the exo-5 mutation must be considered pleiotropic because the mutant cells grew slowly compared with other exo mutants and the wild-type. The infection of $G$. soja with exo mutants and wild-type induced the production of a large number of small pseudonodules. This induction of 

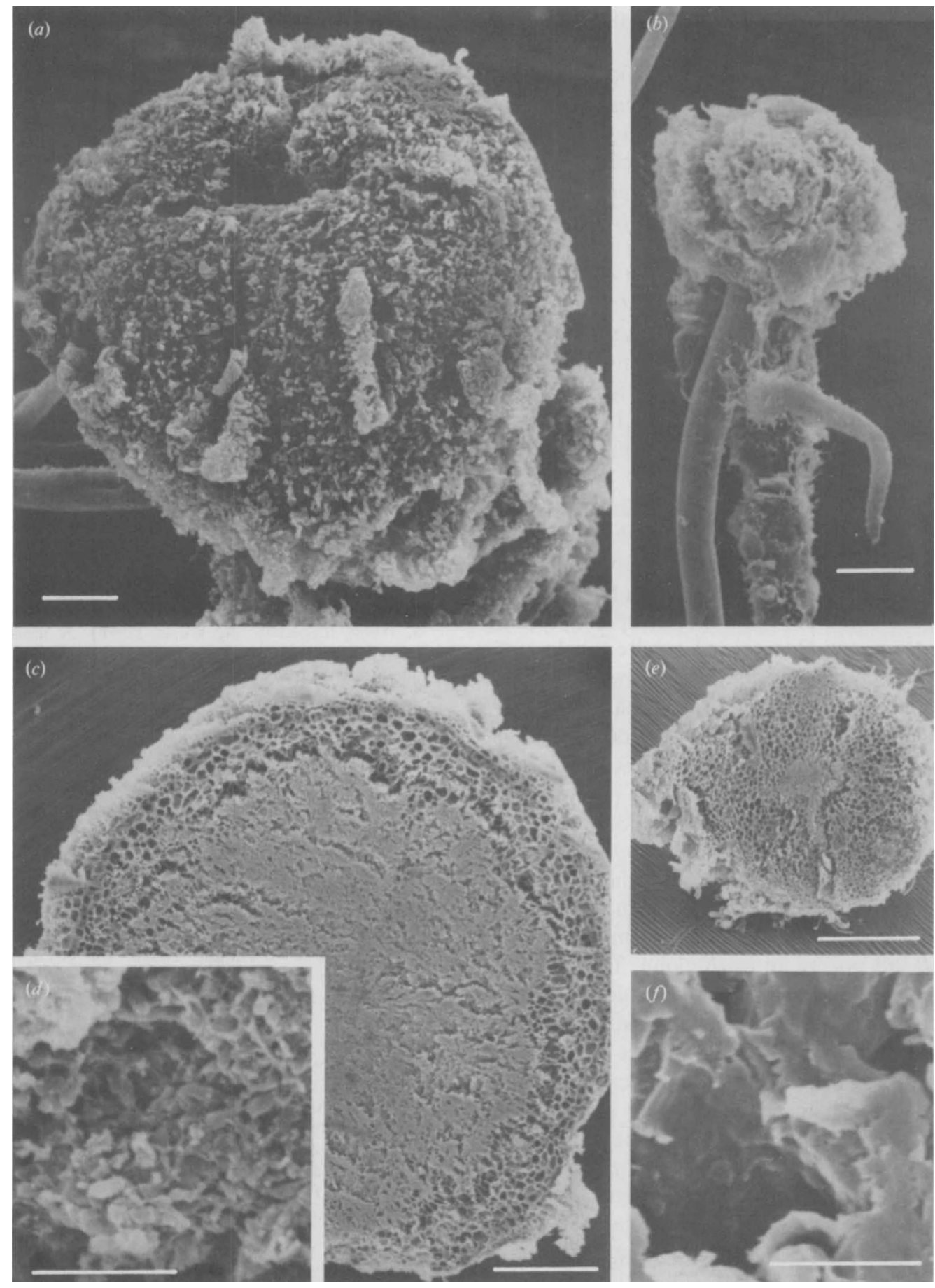

Fig. 4. Scanning electron micrographs of nodules induced in $G$. soja roots by $R$. fredii USDA 191. $(a, b)$ Typical nodule and atypical nodule induced in $G$. soja roots by $R$. fredii USDA 191 after 4 weeks growth. (c) Cross-section of typical nodule and $(d)$ enlargement of typical nodule centre. (e) Cross-section of atypical nodule and $(f)$ enlargement of atypical nodule centre. Bar, $500 \mu \mathrm{m}(a, b, c$ and $e$ ); bar, $5 \mu \mathrm{m}(d$ and $f)$. 
plant cell differentiation without concomitant bacterial invasion indicates that it is not a preferred plant host of $R$. fredii USDA 191.

We tested nodulation on a different soybean species, G. $\max$ (Peking). Correlating with G. $\max$ being a preferred host for $R$. fredii, there was an increased number of nodules per plant root, an absence of atypical nodules upon wild-type infection and a lower number of atypical nodules from exo mutant infections. YKL$293($ exo-5) was able to induce nodules on $50 \%$ of the infected roots of this soybean. However, two different exo mutants, YKL224 (exo-1) and YKL257 (exo-2), were very inefficient in nodule formation in G. max, though a normal nodule could be found in one of ten plant roots infected. Interestingly, two mutants that displayed low production of neutral glucan fractions, YKL285 (exo-3) and YKL293 (exo-5), induced a large number of atypical nodules in G. max.

We tested for exopolysaccharide complementation by $R$. meliloti exo gene clones because Rhizobium species may share common pathways in exopolysaccharide synthesis. YKL293 (exo-5) was complemented by a $R$. meliloti exoC gene clone. This was a pleiotropic mutation that affected strain growth rate and resulted in loss of both the high-molecular-mass acidic exopolysaccharides and the low-molecular-mass neutral glucans. Significantly, the phenotype of the exoC mutant of $R$. meliloti 1021 is similar to exo-5. The exoC mutant was also pleiotropic, grew slowly and produced little if any acidic or neutral polysaccharide (Leigh \& Lee, 1988). Furthermore, recent studies of Agrobacterium tumefaciens indicate that it has a gene, $p s c A$, that is closely related to exoC and a psc $A$ mutant was defective in $\beta$-glucan production (Kamoan et al., 1989). YKL288 was complemented by $R$. meliloti exo $F / B$ but not by an exoB clone. This mutant was defective in the synthesis of the high-molecular-mass acidic polysaccharides but synthesized neutral glucans at about $25 \%$ of normal. The exoF mutant $R$. meliloti appears to have a similar phenotype because it was defective in succinoglycan production but still synthesized $\beta$-glucans (Leigh \& Lee, 1988). Thus it is probable that the exo-3 and exo-5 mutations of $R$. fredii are in genes from a common pathway in exopolysaccharide synthesis. However, these probably similar exo gene mutations affect induction of nodules differently when in $R$. fredii USDA 191 compared to when in $R$. meliloti 1021.

We conclude that a requirement for exopolysaccharide production is not as critical in the formation of determinate nodules as it is for formation of indeterminate nodules. This probably relates to the distinctly different mechanisms of morphogenesis observed for the two forms of nodules (Goodchild, 1977; Newcomb, 1981).
We thank Ray Tully for providing G. soja and G. max seeds and also the $R$. fredii strain, Gram Walker for providing us with exo gene clones of $R$. meliloti, and Cindy Henk and Marion Socolofsky for assistance with electron microscopy and photography. We also thank Michael Orlowski and Eric Achberger for critical reading of the manuscript.

This work was supported by a grant from the Louisiana State University Agricultural Experiment Station. Hatch project LAB02450 to Agricultural Experiment Station.

\section{References}

Aman, D., McNeil, M., Frazen, L., Darvill, A. \& Albersheim, P. (1981). Structural elucidation, using HPLC-MS and GLS-MS, of the acidic polysaccharide excreted by Rhizobium meliloti 1021. Carbohydrate Research 95, 263-282.

appelbaum, E. R., Johansen, E. \& Chartrain, N. (1985). Symbiotic mutants of USDA 191, a fast-growing Rhizobium that nodulates soybeans. Molecular and General Genetics 201, 454-461.

ASHWELL, G. (1966). New colorimetric methods for sugar analysis. Methods of Enzymology 8, 85-94.

Barbour, W. M., Mathis, J. N. \& Elkan, G. H. (1985). Evidence for plasmid- and chromosome-borne multiple nif genes in Rhizobium fredii. Applied and Environmental Microbiology 50, 41-44.

Bonn, G., Grunwald, M., Scherz, H. \& Blobleter, O. (1986). Thinlayer electrophoretic behaviour of oligo- and mono-saccharides, uronic acids and polyhydroxy compounds obtained as biomass degradation products. Journal of Chromatography 370, 485-493.

Borthakur, D., Barber, C. E., Lamb, J. W., Daniels, M. J., Downie, J. A. \& Johnston, A. W. B. (1986). A mutation that blocks exopolysaccharide synthesis prevents nodulation of peas by Rhizobium leguminosarum but not of beans by $R$. phaseoli and is corrected by cloned DNA from Rhizobium or the phytopathogen Xanthomonas. Molecular and General Genetics 203, 320-323.

Cangelosi, G. A., Hung, L., Puvanesarajah, V., Stacey, G., Ozga, D. A., Leigh, J. A. \& Nester, E. W. (1987). Common loci for Agrobacterium tumefaciens and Rhizobium meliloti exopolysaccharide synthesis and their roles in plant interaction. Journal of Bacteriology 169, 2086-2091.

Chen, H. M., Redmond, B. J. \& Rolfe, B. G. (1985). Alteration of the effective nodulation properties of a fast growing broad host range Rhizobium due to changes in exopolysaccharide synthesis. Journal of Plant Physiology 120, 331-349.

Ditta, G., Stanfield, S., CoRbin, D. \& Helinski, D. R. (1980). Broad host range DNA cloning system for Gram-negative bacteria: construction of a gene bank of Rhizobium meliloti. Proceedings of the National Academy of Sciences of the United States of America 77, 7347-7351

Djordjevic, S. P., Chen, H., Batley, M., Redmond, J. W. \& Rolfe, B. G. (1987). Nitrogen fixation ability of exopolysaccharide synthesis mutants of Rhizobium sp. strain NGR234 and Rhizobium trifolii is restored by the addition of homologous exopolysaccharides. Journal of Bacteriology 169, 53-60.

Downie, J. A. \& Johnston, A. W. B. (1986). Nodulation of legumes by Rhizobium: the recognized root? Cell 47, 153-154.

Dudman, W. F. \& Jones, A. J. (1980). The extracellular glucans of Rhizobium japonicum strain 3I1b71a. Carbohydrate Research 84, 358-364.

Finan, T. M., Hirsch, A. M., Leigh, J. A., Johansen, E., Kuldau, G. A., Deegan, S. \& Walker, G. C. (1985). Symbiotic mutants of Rhizobium meliloti that uncouple plant from bacterial differentiation. Cell 40, 869-877.

Gardiol, A. E., Hollingsworth, R. I. \& Dazzo, F. B. (1987). Alterations of surface properties in a Tn5 mutant strain of Rhizobium trifolii 0403. Journal of Bacteriology 169, 1161-1167.

GoodCHILD, D. J. (1977). The ultrastructure of root nodules in relation to nitrogen fixation. In International Review of Cytology, supplement 6. Studies in Ultrastructure, pp. 235-288. Edited by G. H. Bourne, J. F. Danielli \& K. W. Jeon. New York: Academic Press.

Halverson, L. J. \& Stacey, G. (1986). Signal exchange in plantmicrobe interactions. Microbiological Reviews 50, 193-225. 
Heron, D. S. \& PueppKe, S. G. (1984). Mode of infection, nodulation specificity, and indigenous plasmids of 11 fast-growing Rhizobium japonicum strains. Journal of Bacteriology 160, 1061-1066.

Hom, S. S. M., Uratsu, S. L. \& Hoang, F. (1984). Transposon Tn5induced mutagenesis of Rhizobium japonicum yielding a wide variety of mutants. Journal of Bacteriology 159, 335-340.

Huber, T. A., Agarwal, A. K. \& Keister, D. L. (1984). Extracellular polysaccharide composition, ex planta nitrogenase activity, and DNA homology in Rhizobium japonicum. Journal of Bacteriology 158 , $1168-1171$.

Hynes, M. F., Simon, R., Muller, P., Neihaus, K., Labes, M. \& PUHLER, A. (1986). The two megaplasmids of Rhizobium meliloti are involved in the effective nodulation of alfalfa. Molecular and General Genetics 202, 356-362.

Jagadish, M. N. \& Szalay, A. A. (1984). Directed transposon Tn5 mutagenesis and complementation in slow-growing, broad host range cowpea Rhizobium. Molecular and General Genetics 196, 290-300.

Kamoan, S., COOley, M. B., RogowsKy, P. M. \& Kado, C. I. (1989). Two chromosomal loci involved in production of exopolysaccharide in Agrobacterium tumefaciens. Journal of Bacteriology 171, 1755-1759.

KeEN, N. T. \& StaSKawicz, B. (1988). Host range determinants in plant pathogens and symbionts. Annual Review of Microbiology 42 , $421-440$.

KeYser, H. H., BohloOL, B. B., HU, T. S. \& Weber, D. F. (1982). Fastgrowing rhizobia isolated from root nodules of soybean. Science $\mathbf{2 1 5}$, 1631-1632.

LEARY, J. J., BRIGATI, D. J. \& WARD, D. C. (1983). Rapid and sensitive colorimetric method for visualizing biotin-labeled DNA probes hybridized to DNA or RNA immobilized on nitrocellulose: Bioblots. Proceedings of the National Academy of Sciences of the United States of America 80, 4045-4049.

LEIGH, J. A. \& LEE, C. C. (1988). Characterization of polysaccharides of Rhizobium meliloti exo mutants that form ineffective nodules. Journal of Bacteriology 170, 3327-3332.

Leigh, J. A., Signer, E. R. \& W ALKeR, G. C. (1985). Exopolysaccharide-deficient mutants of Rhizobium meliloti that form ineffective nodules. Proceedings of the National Academy of Sciences of the United States of America 82, 6231-6235.

Leigh, J. A., Reed, J. N., Hanks, J. F., Hirsch, A. M. \& Walker, G. C. (1987). Rhizobium meliloti mutants that fail to succinylate their calcofluor-binding exopolysaccharide are defective in nodule invasion. Cell 51, 579-587.

Lim, S. T. \& Shanmugam, K. T. (1979). Regulation of hydrogen utilization in Rhizobium japonicum by cyclic AMP. Biochimica et Biophysica Acta 584, 479-492.

LiM, S. T. \& TAN, E. L. (1983). Exopolysaccharides and lipopolysaccharides from a fast-growing strain of Rhizobium japonicum (USDA 191). FEMS Microbiological Letters 22, 53-56.

Maniatis, T., Fritsch, E. F. \& Sambrook, J. (1982). Molecular Cloning: a Laboratory Manual. Cold Spring Harbor, N.Y: Cold Spring Harbor Laboratory.

MORRIS, D. L. (1948). Quantitative determination of carbohydrates with Dreywood's anthrone reagent. Science 107, 254-255.

MORT, A. J. \& BAUER, W. D. (1980). Composition of capsular and extracellular polysaccharides of Rhizobium japonicum: changes with culture age and correlations with binding of soybean seed lectin to the bacteria. Plant Physiology 16, 158-163.
Mort, A. J. \& Bauer, W. D. (1982). Application of two new methods for cleavage of polysaccharides into specific oligosaccharide fragments: structure of the capsular and extracellular polysaccharides of Rhizobium japonicum that bind soybean lectins. Journal of Biological Chemistry 257, 1870-1875.

NewCOMB, W. (1981). Nodule morphogenesis and differentiation. In International Review of Cytology, supplement 13. Biology of the Rhizobiaceae, pp. 247-297. Edited by K. L. Giles \& A. G. Atherly. New York: Academic Press.

Noel, K. D., Vandenbosch, K. A. \& KulpaCa, B. (1986). Mutations in Rhizobium phaseoli that lead to arrested development of infection threads. Journal of Bacteriology 168, 1392-1401.

PuePrKe, S. G. (1983). Rhizobium infection threads in root hairs of Glycine max (L.) Merr., Glycine soja Sieb, and Zucc., and Vigna unguiculata (L.) Walp. Canadian Journal of Microbiology 29, 69-76.

Postek, M. T., Howard, K. S., Johnson, A. H. \& MCMichael, K. L. (1980). Specimen preparation in scanning electron microscopy. In $A$ Students Handbook, pp. 115-240. New York: Ladd Research Industries.

Robertsen, B. K., Aman, P., Darvill, A. G., McNeil, M. \& AlBersheim, P. (1981). Host-symbiont interactions: the structure of acidic extracellular polysaccharides secreted by Rhizobium leguminosarum and Rhizobium trifolii. Plant Physiology 67, 389-400.

SCHWINGHAMER, E. A. (1960). Studies on induced variation in the Rhizobia: I. Defined media and nodulation test techniques. Applied Microbiology 8, 349-352.

SelvaraJ, G. \& IYer, V. N. (1984). Transposon Tn5 specifies streptomycin resistance in Rhizobium spp. Journal of Bacteriology 158, 580-589.

SHER WOOD, M. T. (1970). Improved synthetic medium for the growth of Rhizobium. Journal of Applied Bacteriology 33, 708-713.

Simon, R., Priefer, U. \& Puhler, A. (1983). A broad host range mobilization system for in vivo genetic engineering: transposon mutagenesis in Gram-negative bacteria. Biotechnology 1, 784-791.

Tsien, H. C. \& SchmidT, E. L. (1981). Localization and partial characterization of soybean lectin-binding polysaccharide of Rhizobium japonicum. Journal of Bacteriology 145, 1063-1074.

TULLY, R. E. (1985). New culture media to suppress exopolysaccharide production by Rhizobium japonicum. Applied Microbiology and Biotechnology 21, 252-254.

Vandenbosch, K. A., Noel, K. D., Kaneko, Y. \& Newcomb, E. H. (1985). Nodule initiation elicited by noninfective mutants of Rhizobium phaseoli. Journal of Bacteriology 162, 950-959.

VERMA, D. P. S. \& NADLER, K. (1984). Legume-Rhizobium symbosis: host's point of view. In Genes Involved in Microbe-Plant Interactions, pp. 57-93. Edited by D. P. S. Verma \& T. Hohn. Wien, New York: Springer-Verlag.

WAHL, G. M., Stern, M. \& Stark, G. R. (1979). Efficient transfer of large DNA fragments from agarose gels to diazobenzyloxymethylpaper and rapid hybridization by using dextran sulfate. Proceedings of the National Academy of Sciences of the United States of America 76, 3683-3687.

York, W. S., MCNeil, M., Darvill, A. G. \& Albersheim, P. (1980). Beta-2-linked glucans secreted by fast-growing species of Rhizobium. Journal of Bacteriology 142, 243-248. 